\title{
An unusual case of dense unilateral epidural block and the subsequent presentation of tinnitus as a post dural puncture symptom
}

Samson Ma', Dominic O'Connor², Jay Dasan ${ }^{3}$

Department of Obstetric Anaesthesia, King's College Hospital NHS Foundation

Trust, London, United Kingdom

1. Obstetric Anaesthesia Fellow, King's College Hospital, London

2. Anaesthetic Specialty Registrar, King's College Hospital, London

3. Consultant Anaesthetist, King's College Hospital, London

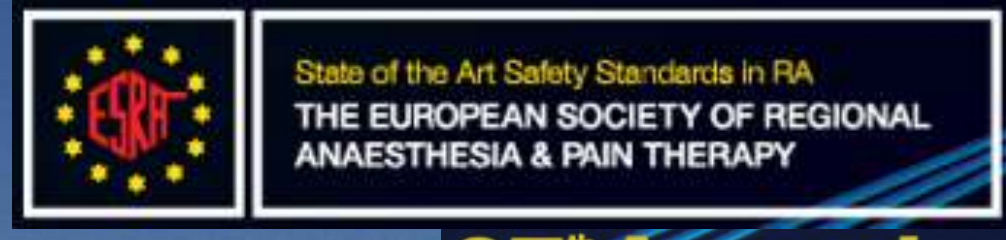

\section{Introduction}

Case reports remain an important resource in clinical education[1]. Unilateral, patchy blocks or failures of epidurals are commonly encountered for various reasons[2], [3]. These may include inexperienced operator, patient factors such as anatomical anomalies and patient conditions that lead to technical difficulties [3]. We describe a previously unreported pattern of unilateral supra-normal motor and sensory block with a normal contralateral epidural block in an obstetric patient.

\section{Obstetric history}

33-year-old, 41+3 Gestation, G1P0 primagravid lady of low risk pregnancy presenting with spontaneous labour.

\section{Epidural}

After consent, $1^{\text {st }}$ attempt at $L 3 / 4$ in seated position. Loss of resistance (LOR) to saline at $5.5 \mathrm{~cm}$, but resistance felt when inserting the catheter, so insertion was re-attempted at the same level. $2^{\text {nd }}$ insertion attempt, LOR at $5.5 \mathrm{~cm}$ with catheter passing unhindered, leaving $4.5 \mathrm{~cm}$ in situ following negative aspiration.

\section{Bolus}

Test dose of $10 \mathrm{ml}(0.1 \%$ Bupivacaine $+2 \mathrm{mcg} / \mathrm{ml}$ Fentanyl) was given. Unilateral right-sided leg weakness was felt within 5 minutes with MRC (Medical Research Council) grading of 2 throughout the right leg and 5 throughout contra-laterally. Sensory to cold were T12 on the left and T8 on the right. There were no haemodynamic instabilities.

\section{Management of epidural \& plans for C-Section}

This unusual presentation raised the possibilities of the catheter tip being in the subdural space or partially in the intrathecal space. We managed her analgesia with the described low dose mixture titrated manually. This was to be done by the duty anaesthetist only and the patient was told not to use the patient controlled epidural analgesia. We planned to remove the catheter and insert a spinal anaesthetic in the event of a emergency $\mathrm{C}$-section because the dose would not be predictable for surgical anaesthesia using the method of epidural top up.

\section{Labour outcome}

The analgesia was excellent and the patient delivered a healthy baby boy approximately 6 hours after the insertion of the epidural with 2 separate $5 \mathrm{ml}$ boluses of low dose mixture, an average of 1 bolus in every 2 hours.

\section{Clinical Course- Postpartum}

Day 1- No headache. The patient did however experience tinnitus, a symptom that was unprompted by the anaesthetist. As a post dural puncture headache was expected, this raised a possibility of a cranial nerve symptom as a feature of the dural puncture. She was discharged from the postnatal care and wanted to return home. We discharged her home with the advice to return if a headache developed.

Day 2- The patient returned with a severe postural headache and continuing tinnitus without other cranial nerves involvement. She was managed conservatively initially on the postnatal ward.

Day 4- Headache reduced but there was persisting tinnitus. As patient continued to have symptoms of a PDPH, an epidural blood patch was offered. After patient consent the procedure was carried out the same day.

\section{Epidural blood patch}

An epidural blood patch was performed with the patient in the left lateral position. It was attempted at L4/5- visually one level below the previous puncture site. LOR to saline at $5 \mathrm{~cm}$ confirmed the space and overall $40 \mathrm{ml}$ of blood was injected without pain or resistance. 2 hours after the procedure the patient was allowed to ambulate and she reported complete resolution of symptoms. A telephone follow up was arranged and she remained asymptomatic on day 5 post partum.

\section{Discussion}

This unusual block pattern had not been previously reported. Post dural puncture can present with unusual neurological symptoms without headache initially. These symptoms must be identified at follow up. Early detection would have resulted in more timely intervention and resolution of symptoms. High index of suspicion and vigilance are crucial in identifying complications following epidurals.

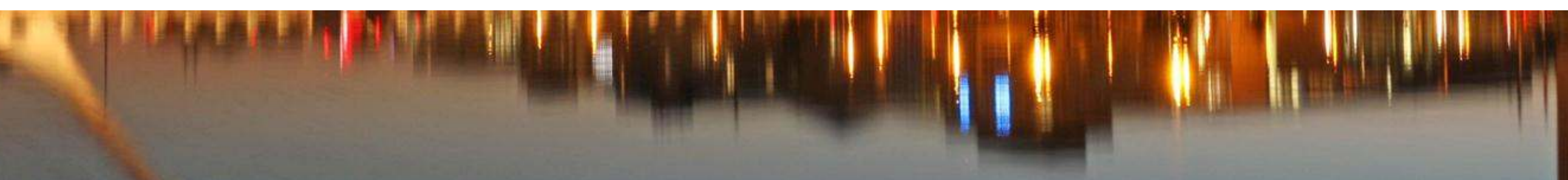

References

1. R Russell. Case reports and consent to publication, Int Journal of Obstetric Anaesthesia, 2016 (28):1-2

2. AR Moore, N Siddiqui, EE Kassel, JC Carvalho. Unintentional subdural catheter placement during labor analgesia shows typical radiological pattern but atypical response to the Tsui test. Int J Obstetric Anaesthesia, 2010 Jan;19(1):111-4

3. K Arendt, S Segal. Why epidurals do not always work? Rev Obstetrics \& Gynaecology, 2008 Spring; 1(2):49-55 